\title{
Internet and its impact on the market position of telecom operators
}

\author{
Maciej Czaplewski ${ }^{1, *}$ \\ ${ }^{1}$ University of Szczecin, Faculty of Management and Economics of Services, 64 Mickiewicza St., \\ 71-004 Szczecin, Poland
}

\begin{abstract}
Telecom operators specialize in the provision of information and communication (IC) services. For a long time they have the potential to provide traditional services, including voice and text messages, which are being constantly improved, primarily due to the progress in information and communication technologies (ICT). The progress in ICT and the offer of IC services in recent years is related to the implementation and development of Internet. In consequence the traditional offer of IC services is extended by innovative services enabling the transmission of voice, data and images. At the same time, these services are starting to be provided not only by telecom operators but also by other entities, in particular the so-called Over The Top (OTT) operators, including Google, Facebook, Amazon etc.
\end{abstract}

\section{Introduction}

The progress in information and communication technologies (ICT) and the offer of information and communication (IC) services in recent years is strong connected with the development of Internet. Next to traditional telecom operators new service providers are from different branches are beginning to appear on this market. In consequence, this leads to growing competition in the area of providing innovative information and communication services. This means the emergence of new issues that need to be recognized, which can be formulated in the form of the following research questions:

- what are the basic reasons for using Internet by telecom operators?

- what impact does Internet have on the offer of information and communication services?

- what may be the consequences of changes in the structure of information and communication services to the market position of telecomm operators?

Attempting to answer these questions, in the article, the following research methods were used:

- method of critical literature analysis,

- method of observing market activities of telecommunications operators,

- logical inference method,

- method of analysis and synthesis.

\footnotetext{
*Corresponding author: maciej.czaplewski@,wzieu.pl
} 


\section{Internet as an innovative information and communications technology}

Internet is a new information and communication technology. Definitions presented in the literature are usually limited to showing its network character. The most common are the following two ways to define the Internet as:

- a network of networks based on the TCP / IP protocol [1, 2],

- a network connecting computers based on the TCP / IP standard [3, 4].

Definitely less often in the literature you can find a broader definition of the Internet, which present it as:

- a collection of offered services and applications that enable the transmission of information and data, as well as the information and data itself,

- a set of users using the shared networks and the offered services and applications that enable the transmission of data and information.

Examples of such Internet coverage are definitions presented by:

- E. Kroll and E. Hoffman, who, while presenting the concept of the Internet, indicate that in addition to technical components, it is necessary to take into account the provided information and the potential of people using the technical tools as well as provided information [5],

- J. Wielki, who indicates the need to consider the Internet from three following points of view:

- technical - as a network based on the TCP / IP protocol,

- $\quad$ social - people using internet networks,

- practical - including the pool of knowledge, information and services that can be obtained through a particular network [6].

An important effect of using the Internet are certain usabilities affecting the way entities operate in the area of economic and social life. These include, in particular [4, 7]:

- interactivity, that:

- enables individual selection, matching and use of content available on the Internet, which ensures maximum usability for individual Internet users,

- can be reduced to a simple, single contact as well as an extensive, repeatable dialogue between multiple users,

- provides benefits to internet service providers as well as to users of these services (as providers can relatively cheap create and offer collections of information individually tailored to the needs of individual recipients and users can assemble sets of information from individual configured sets of information according to their own needs and interests),

- is a source of its advantage over such media as radio, television and the press, where one party is the sender and the other only the recipient of information,

- $\quad$ is very important for: coordination activities (Coordination), trade (Commerce), development of online communities (Community), presentation of content (Content) and communication methods (Communication);

- direct character and lack of time limits in access to content, making possible:

- that the desired information can be obtained by the users at the most appropriate time, which results in obtaining information that is particularly valuable,

- to find the most convenient connection time between entities that want to communicate with each other or cooperate;

- multimediality of offer - manifested by the diversity of Internet offer forms and using transfer possibilities by such different means like voice, video, text, images and graphics;

- relative ease of use of the Internet offer - resulting from the following basic reasons:

- Internet users use the same technique, 
- information is sent and received using the same protocol and can be practically sent from anywhere in the world and delivered to any place in the world.

The basic internet utilities mentioned above have a strong impact on the sphere of economic and social life, offering in both these areas new, previously unknown possibilities of obtaining information and ways of communication between entities. The Internet should therefore be treated as an information and communication technology with a complex internal structure whose usability affects the sphere of economic and social life.

The presented features and usabilities allow us to consider the Internet as a general purpose technology, with the following features $[1,8,9]$ :

- they constitute a technological base for a wide range of existing and potential products and production processes (pervasiveness),

- they have (own) significant innovative potential expressed by the implementation of process and product innovations (improvement),

- they show positive impacts due to introduced innovations as well as due to mutual interactions between individual innovative applications (innovation spawning).

\section{Basic reasons for using internet by telecom operators}

The growing demand for internet services in connection with the necessary role of telecommunications networks in order to ensure universal access to these services leads to transformations in the structure of telecommunications networks especially as a result of adapting existing networks to the IP standard and building modern networks meeting these standards. Activities leading to the use of IP-based networks are provided not only by telecom operators (stationary and mobile), but also by other operators, especially the Internet and cable television ones. The consequence of these activities is entering the next stage of network convergence, including various information and communication networks, including in particular networks of telecom, internet and cable television operators.

The emerging convergent information and communication networks allow to offer a wide range of services, including:

- classic telecommunications services (e.g. voice telephony, SMS),

- classic internet services (e.g. information services obtained from websites as well as communication services, such as VoIP, chat rooms),

- Internet services requiring networks with higher quality parameters (e.g. audio and video services).

Listed services, being at the same time, modern substitutes for classic telephony and television services, are beginning to exert strong pressure on traditional activity areas of telecom and cable television operators [10].

This means that the development of the Internet leads to the acceleration of convergence processes in the area of information and communication networks, information and communication services and end devices used by users of information and communication services. These processes overlap, accelerating their further development direction. In graphical terms, this is shown in Fig. 1. 


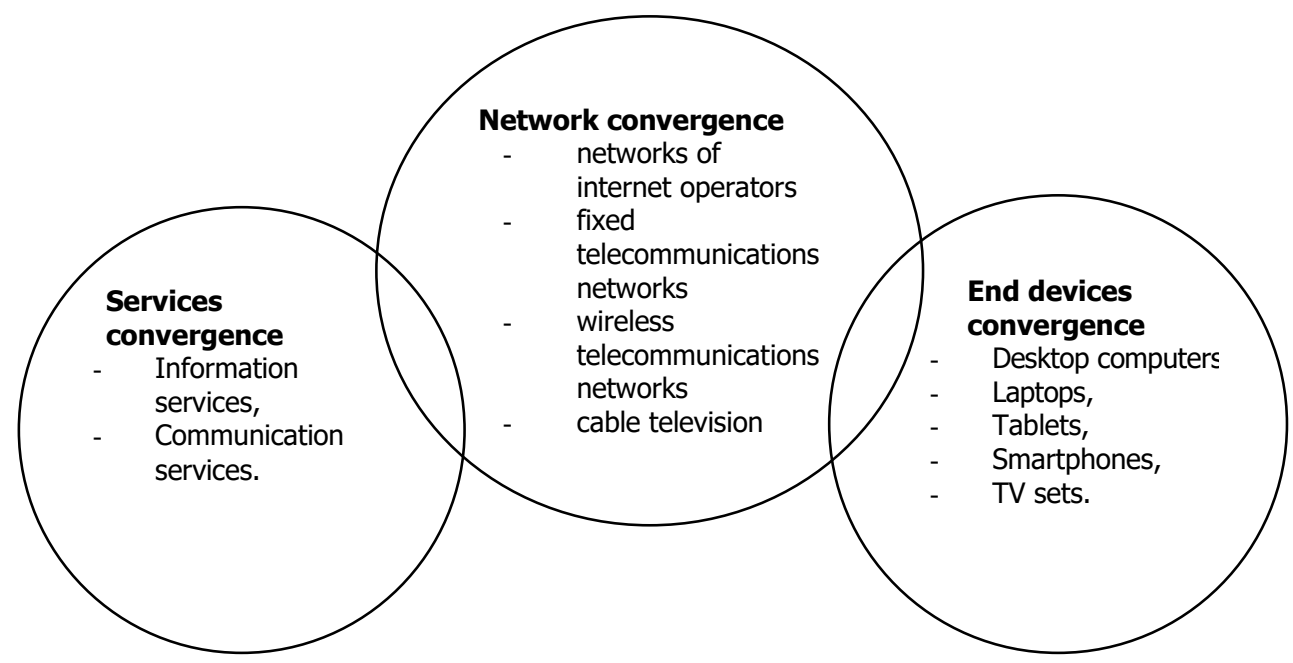

Fig. 1. The basic areas of progressive convergence associated with the development of the Internet. Source: own elaboration.

Fig. 1. shows that convergence based on the Internet can be described as second-degree convergence, which:

- strengthens existing telecommunications and IT connections,

- builds telecommunications and cable television connections.

At the same time, it should be noted that following the development of the Internet, its impact on the connection between the fixed-line market, the mobile phone market and the cable TV market is becoming more intense. Also new telecommunications products, ranging from unique innovations resulting from multi-site advanced technological research, to modifications of existing ones, are emerging [11]. In consequence it leads to:

- increase in the share of data transmission in the activity of fixed-line market and the mobile phone market,

- increase in the share of voice transmission in the activity of cable TV market,

- growing fields of fixed-line market activities overlap with the mobile phone market activities as well as with the cable TV market activities.

\section{Impact of Internet on changes in the offer of services}

Considering the facts that the traditional offer of IC services is extended by innovative services and at the same time, these services are starting to be provided not only by telecom operators but also by other entities, like cable TV operators, Over The Top (OTT) operators (including Google, Facebook, Amazon etc.) as well as by companies from totally different markets, we can say that staying with old solutions, even those ones which allowed telecom companies earlier to become the leader of a given market, hinders them from introducing technology that interrupts the continuity of development [12]. This in consequence may lead to a takeover of their market. For that reason, telecom operators are forced to formulate new market strategies aimed at such use of Internet properties that will allow them to strengthen their position in the telecommunications services market and ensure efficient offering of a full range of modern internet services, including Internet telephony (VoIP) and Internet television (IPTV). Creating conditions for obtaining such effects first of all requires the emphasis on: 
- investing in network technologies in order to provide customers with a service offer that meet or even exceed their requirements,

- development of business models that take into account newly formulated tasks, including services that promise the best development prospects, rules for their implementation and related organizational transformations necessary in the company structure,

- analyzing the behavior of users of information and communication services, in order to obtain information on the services and products they expect, focus on providing these services and products and search for and implement service and solutions that anticipate these expectations,

- analyzing regulatory solutions applicable in the area of providing information and communication services and the possibility of their use in the company's development process, examining proposed regulatory solutions from the point of view of their possible impact on the chances and threats of the company's functioning and preparing their own suggestions regarding the amendment of existing regulatory solutions, presenting them to the regulator sector to consider as well as possibly refer to the implementation procedure.

The demand for innovative information and communication services depends on the interest of final customers. This interest, in turn, is strongly related to the usefulness of these services and the opportunities offered by the market for the selection of their suppliers.

An important indicator of the usefulness of innovative information and communication services are the features that distinguish these services from traditional telecommunications services, which is in general presented in Table 1.

Table 1. Basic features distinguishing innovative information and communication services from traditional telecommunications services.

\begin{tabular}{|l|l|}
\hline traditional telecommunications services & Innovative information and communication services \\
\hline voice transmission & expanded offer of voice services \\
\hline simple data transfer & multimedia services \\
\hline limited access to services & access via various end devices \\
\hline lack of interactivity & the possibility of interactive use of services \\
\hline standard quality & scalable quality (e.g. choice of data transfer rate) \\
\hline universal offer & offer tailored to the customer's needs \\
\hline
\end{tabular}

Source: own elaboration on the base of [13].

The increased and extended usabilities of innovative information and communication services are important development impulses supporting economic and social activity. The potential of the Internet and related innovative information and communication services is also due to the fact that:

- it leads to the emergence of new markets (e.g. e-commerce, Internet of Things),

- facilitates access to these markets.

\section{Potential consequences of changes in the structure of information and communication on telecom operators market position}

The development of the Internet and innovative services offered in conjunction with its development translate into changes not only on the supply side of telecommunication market, but also changes in the market behavior of information and communication services consumers and the demand reported by them.

These changes make the Internet an increasingly important factor that binds individual used communication systems and communication services provided. As a consequence, at 
today's telecommunication market transforming into the market of information and communication, two following development trends are strengthening:

- accelerated convergence through the internet,

- growing role of internet services.

Accelerated convergence taking place thanks to the Internet on the one hand is manifested by the acceleration of fixed and mobile telephony interpenetration. On the other hand, it leads to the emergence and market strengthening of Over the Top operators offering such specialized services as e.g. video streaming, messaging and cloud services that increasingly substitute telecom operators' services. This prompts these operators to offer not only classic fixed-line and mobile telephony services, but also:

- inclusion in the offer and provision of new services, e.g. IPTV, VoIP, applications, content services,

- offering tangible products enabling the use of new services, such as smartphones, tablets, Live Box.

At the same time, offering a wide range of services via modern networks that enable not only transmission of voice, but also images and data, allows the network to achieve economies of scope activities. These benefits should primarily be connected with the possibilities of:

- broadening the competence of operators, including obtaining complementary competences,

- developing new business fields based on acquired new competences,

- achieving the effects of business diversification and combining diversified activities in order to achieve synergetic effects.

Orientation of telecom operators and other information transmission markets to increase the scale of operations and the scope of activities, motivated primarily by economic considerations, leads to increasing competition between operators providing information and communication services. This process involves the permanent emphasis on innovation and development. In this situation, an essential complement to the increase in the scale of operations and the scope of activities must be:

- $\quad$ speed of operation (Economies of Speed) [14, 15, 16], which requires:

- ongoing analysis of new scientific solutions,

- intensive implementation of modern technological and organizational solutions that promise market success,

- continuous research and recognition of the needs and expectations of contemporary customers as well as the development of offers that best meet these needs and expectations,

- the best possible use of qualifications and skills potential (Economies of Skills) in order to develop:

- innovative service offers with high added value and

- modern customer service systems characterized by high quality and convenience (simplicity) of use.

Achieving and maintaining a significant position on the modern telecommunication market, strongly associated with the electronic media market and evolving into the market of information and communication, therefore requires from telecom operators undertaking actions aimed at simultaneous obtaining:

- economies of scale,

- benefits of the scope of activity,

- benefits resulting from the rapid implementation of innovative information and communication solutions, 
- benefits of having an innovative knowledge that allows to create an attractive service offer, characterized by high added value and modern service systems with high quality and simplicity of use.

\section{Final remarks}

All the considerations indicate on the growing importance of OTT services. They also point out that OTT services and telecommunications services are not only complementary ones. Some OTT services and classic telecommunications services are substitutes. Taking into account page restrictions as well as essential limitations we can say, that this is an interesting topic for further considerations (in subsequent articles). At this point the conducted research allowed to state that OTT services and telecommunications operators' services are subject to different regulatory solutions. Telecom operators' services are much more strictly regulated. Maintaining this state may result in:

- a decline in the market role of telecom operators,

- forcing telecom operators to act as network providers for other entities offering information and communication services.

In this situation, the author suggests the need to approximate the regulations applicable to OTT and telecommunications operators by easing solutions covering the latter ones.

\section{References}

1. P. Lovelock, J. Ure, The New Economy: Internet Telecommunications and Electronic Commerce?, in: Handbook of New Media (Sage Publications, London, Thousand Oaks, New Delhi, 2002)

2. M. Rost, M. Schack, DFU - Ein Handbuch, Recherchen In weltweiten Netzen (Heise, Hannover, 1993)

3. A. Kobyliński, Ekonomiczne Problemy Usług, no 112 (2014)

4. A. Afuah, Ch.L. Tucci, Biznes internetowy. Strategie i modele (Oficyna Ekonomiczna, Kraków, 2003)

5. E. Krol, E. Hoffman, “What is the Internet?”, http://tools.ietf.org/html/rfc1462.html

6. J. Wielki, Elektroniczny marketing poprzez Internet (Wydawnictwo Naukowe PWN, Warszawa-Wrocław, 2000)

7. A. Zerdick, A. Picot, K. Schrappe, A. Artope, K. Goldhammer, U.T. Lange, E. Vierkant, E. Lopez-Escobar, R. Silverstone, Die Internet Ökonomie. Strategien für die Digitale Wirtschaft, European Communication Council Report (Springer Verlag, Berlin, Heidelberg, 1999)

8. T.F. Bresnahan, General purpose technologies, in: B.H. Hall, N. Rosenberg (ed.), Handbook of the Economics of Innovation (Elsevier, Oxford, 2010)

9. T.F. Bresnahan, M. Trajtenberg, Journal of Econometrics 65(1) (1995)

10. A. Małachowski, Zeszyty Nauk. US Ekonomiczne Problemy Usług, 35, (2009)

11. A. Budziewicz-Guźlecka,. Zeszyty Nauk. US. Ekonomiczne Problemy Usług, 35 (2) (2009)

12. C.M. Christensen, Przełomowe innowacje. Możliwości rozwoju czy zagrożenie dla przedsiębiorstwa (Wydawnictwo Profesjonalne PWN, Warszawa, 2010)

13. F. Buellingen, P. Stamm, Diskussionsbeitrag 222, (2001) 
14. E. Altvater, B. Mahnkopf, Grenzen der Globalisierung. Ökonomie, Ökologie und Politik in der Weltgesellschaft. Münster: Westfälisches Dampfboot (1996)

15. PITAC, Information Technology Research: Investing in Our Future. President's Information Technology Advisory Committee (PITAC): Report to the President (ed. by National Coordination Office for Computing Information and Communications), February 24th (1999)

16. R. Ortitz, P. Dadam, The Concurrency Model: Activating an Engineering Database through an Integrated Product and Process Data Model. Paper presented at the 6th Int. Conference and Workshop on Database and Expert Systems Applications DEXA, London UK, September 4th-8th (1995) 